ISSN electrónico: 2172-9077

DOI: http://dx.doi.org/10.14201/fjc201612183204

\title{
LA OFICINA HAYS Y LAS DOS VERSIONES FÍLMICAS \\ MODERNIZADAS DEL CASO MADELEINE SMITH: LETTY LYNTON (1932) Y DISHONORED LADY (1947)
}

\section{The Hays Office and the Two Updated Film Versions of Madeleine Smith's Case: Letty Lynton (1932) and Dishonored Lady (1947)}

\author{
Dra. Carmen GUIRALT GOMAR \\ Universidad de Valencia, España \\ E-mail: carmenguiralt@yahoo.es \\ (i) http://orcid.org/0000-0003-1409-6675
}

Fecha de recepción del artículo: 04/01/2016

Fecha de aceptación definitiva: 02/03/2016

\begin{abstract}
RESUMEN
El célebre caso de Madeleine Smith, la envenenadora de Glasgow, Escocia, que fue juzgada por asesinato (y absuelta) en 1857, ha dado lugar a numerosas novelas, obras teatrales, films y series de televisión. Hollywood durante su periodo clásico realizó dos versiones actualizadas del suceso: Letty Lynton (Letty Lynton, Clarence Brown, 1932) y Dishonored Lady (Amor que redime, Robert Stevenson, 1947). A pesar de estar realizadas con más de una década de diferencia, la autocensura instaurada por los propios estudios norteamericanos -MPPDA y comúnmente aludida como Oficina Hays - ejerció múltiples presiones sobre las dos, con el resultado de que son difícilmente reconocibles como equivalentes. Este artículo propone un análisis comparativo de los dos largometrajes y la acción de la censura sobre ambos, a través del cual se comprobará el diferente ejercicio de la MPPDA frente un mismo material antes y después del sometimiento (auto)obligatorio de Hollywood al Código Hays en julio de 1934.
\end{abstract}

Palabras clave: Madeleine Smith; Letty Lynton; Dishonored Lady; Hollywood; Oficina Hays; autocensura cinematográfica.

\begin{abstract}
The celebrated case of Madeleine Smith, the Glasgow poisoner, who was tried for murder (and absolved) in 1857, has resulted in many novels, plays, films and television series. Hollywood, during its classical period, made two updated versions of the incident: Letty Lynton (Clarence Brown, 1932) and Dishonored Lady (Robert Stevenson, 1947). Even though the two films are separated by more than a decade, the self-censorship introduced by the studios themselves - MPPDA, commonly known as the Hays Office - exercised so much control over the two pictures that they can hardly be taken as equivalent. This article proposes a comparative analysis of the two films and how censorship acted as a constraint on them. Through this study, we will establish the different ways the MPPDA acted towards the same material both before and after July 1934, when Hollywood became subject to the rigorous oversight of the Hays Code.
\end{abstract}

Keywords: Madeleine Smith; Letty Lynton; Dishonored Lady; Hollywood; Hays Office; Film self-censorship. 


\section{INTRODUCCIÓN}

El 23 de marzo de 1857 tuvo lugar en Glasgow, Escocia, uno de los crímenes por asesinato más célebres de la época victoriana. Madeleine Smith, una joven acomodada, hija de un arquitecto, fue acusada de envenenar a su amante francés de clase baja, Pierre Emile L’Angelier. Tiempo después del inicio de su romance secreto, su familia le concertó un matrimonio ventajoso con un caballero de su posición y ella decidió terminar su relación. El francés, que no solo estaba interesado en ella, sino también en su dinero, la amenazó con revelar a su progenitor sus comprometedoras cartas si no era presentado en su casa como su prometido (Brownlow, 1996). Las misivas ponían al descubierto que Madeleine había perdido la virginidad antes del matrimonio y con un aprendiz de jardinero (GonzálezSampedro, 2014). Así pues, dado que L'Angelier suponía un peligro para su honor y podía provocar la disolución de su compromiso, resolvió acabar con su vida y le administró arsénico en el chocolate hasta tres veces, la tercera de las cuales le ocasionó la muerte.

El caso supuso un gran escándalo y tuvo una honda repercusión en la sociedad victoriana, sobre todo por la explícita sexualidad de las cartas, que salieron a la luz en el juicio y causaron gran revuelo al haber sido escritas por una muchacha bien educada (Brownlow, 1996; Knox, 2006; Hartman, 2014; Simkin, 2014). Fue objeto de una exhaustiva cobertura por parte de la prensa de la época, que transcribió con todo lujo de detalles las sesiones ante el tribunal, incluyó las transcripciones de las cartas y lo refirió de forma continuada como "el juicio del siglo" (MacGowan, 1999; Hartman, 2014; González-Sampedro, 2014). Más allá de las fronteras escocesas, su impacto se sintió en todo el Reino Unido (Simkin, 2014; Breitenbach, Fleming, Kehoe \& Orr, 2013). Procesada por tres cargos, dos por intento de asesinato y otro por consumarlo, el dictamen del jurado fue igual de sensacional: inocente de la primera acusación de tentativa y un veredicto de "no demostrado" (not proven), únicamente permitido por los tribunales escoceses, en los otros dos (MacGowan, 1999) (Figura 1). Después del fallo, tuvo que exiliarse del Reino Unido ${ }^{1}$.

Figura 1. Dibujo de la verdadera

Madeleine Smith realizado durante el juicio.

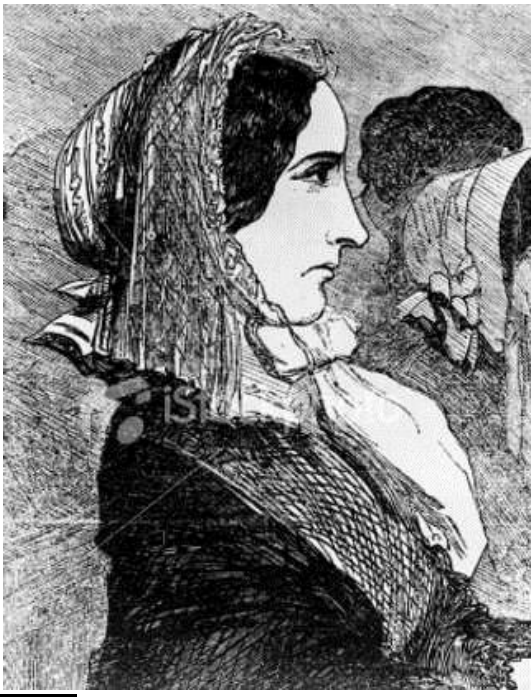

\footnotetext{
${ }^{1}$ De acuerdo con MacGowan (1999, p. ix), este veredicto “[...] a menudo conlleva un estigma, pues no solo indica que la acusación no pudo probar el caso, sino que también señala que la defensa no pudo convencer al jurado de la inocencia del acusado".
}

(C) Ediciones Universidad de Salamanca / CC BY - NC ND Fonseca, Journal of Communication, n. 12, 2016, pp. 183-204 
Transcurridas las décadas, Madeleine Smith, ni culpable ni inocente, continuaba siendo igual de popular (MacGowan, 1999). Había quedado convertida en una celebridad social, objeto de la fascinación pública (Simkin, 2014). Su muerte, el 28 de abril de 1928 en Nueva York, reavivó aún más el interés en su persona.

A comienzos de los años 30 Metro-Goldwyn-Mayer se propuso realizar una versión fílmica y a finales de 1931 adquirió la novela de Marie Belloc Lowndes Letty Lynton (1930)², una ficción que emplazaba los hechos en la era contemporánea. El largometraje, Letty Lynton (Letty Lynton, 1932), fue producido por Hunt Stromberg, dirigido por Clarence Brown y protagonizado por Joan Crawford y Robert Montgomery (Figura 2). Poco después de su distribución comercial, Edward Sheldon y Margaret Ayer Barnes demandaron a la productora y alegaron que plagiaba su obra Dishonored Lady (1930) ("Lynton' Starts Piracy", 1932; "Inside Stuff-Pictures", 1932; Sargent, 1932). Lo cierto es que la dramatización, también actualizada, partía igualmente de la historia de 1857 y el estudio había negociado en inicio con los autores la posibilidad de llevarla a la pantalla. No obstante, la autocensura cinematográfica -Motion Picture Producers and Distributors of America (MPPDA) y popularizada como Oficina Hays- obstaculizó la transacción al tacharla de obscena ("M-G Ducks", 1932; Decherney, 2012; Vieira, 2009). La causa judicial se disputó durante ocho años (1932-1940), pero en 1936 una sentencia estableció el plagio y desde entonces la película se halla prohibida por vía legal ${ }^{3}$.

Figura 2. Cartel publicitario de Letty Lynton (1932).

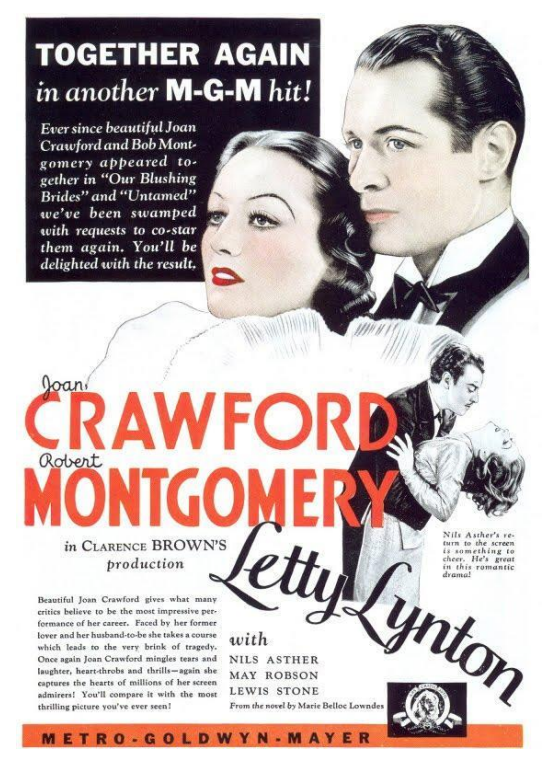

En 1942 Stromberg, convertido en productor independiente, planificó un remake, esta vez legítimo, de la pieza teatral, y en junio adquirió sus derechos ("Much Litigated", 1942; "Dishonored Lady", 1942; "UA Owners", 1942). Pero la autocensura, de nuevo, dificultó el proyecto y reprobó el guion en tantas ocasiones que el rodaje no comenzó hasta mayo de 1946 (The American Film Institute Catalog

\footnotetext{
${ }^{2}$ Publicada por entregas en el London Daily Mail, de mayo a julio de 1930, y en formato libro en 1931.

${ }^{3}$ Para mayor información sobre el proceso judicial, véase Vaidhyanathan, 2003 y Decherney, 2012.
} 
Database 1893-1970 [AFI]'; Barton, 2010). Finalmente, se estrenó en 1947 como Dishonored Lady (Amor que redime), dirigida por Robert Stevenson y protagonizada y co-producida por Hedy Lamarr (Figura 3).

Figura 3. Cartel publicitario de Dishonored Lady (1947).

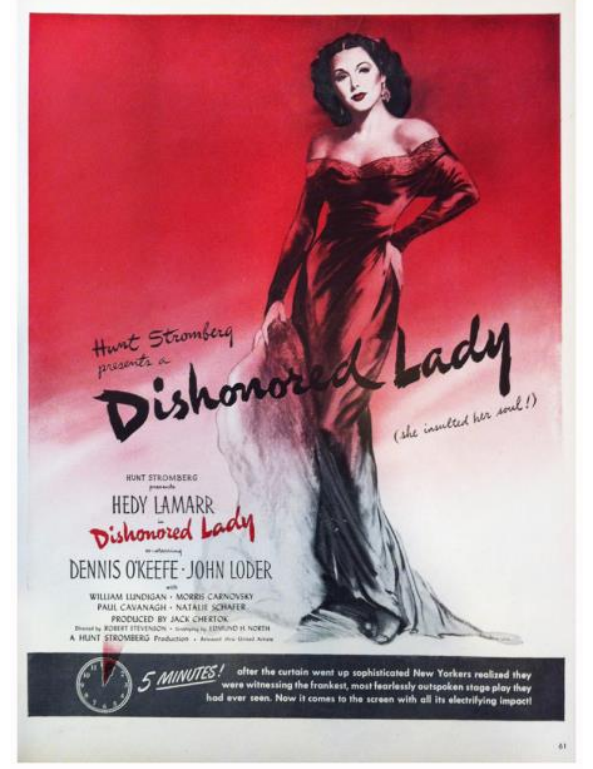

\section{2. ОВJETIVOS E HIPÓTESIS}

El presente texto propone un estudio comparado de Letty Lynton y Dishonored Lady a la luz de las fuentes utilizadas en cada película para configurar sus escenas: sucesos del siglo XIX, obra teatral y novela. El análisis nos permitirá concluir que, a pesar de fundamentarse ambas en los mismos hechos de dominio público -los acontecimientos de 1857- y de estar basadas, parcial o totalmente, apócrifa o legítimamente, en la misma fuente literaria -la dramatización de 1930-, apenas tienen nexos en común y menos aún pueden entenderse como versiones parejas. Demostraremos que el film de 1947 en ningún caso puede considerarse un remake del de 1932, como con frecuencia se ha afirmado en numerosos textos historiográficos (Eyles, 1987; Brownlow, 1996; Barton, 2010; Kabatchnik, 2010; Shearer, 2010; Decherney, 2012).

Al mismo tiempo, verificaremos cómo esta total ausencia de semejanza se debió en gran medida a las presiones de la Oficina Hays, ya que las coacciones fueron de índole muy distinta en cada ocasión.

Por lo tanto, a través de este estudio evidenciaremos la actuación completamente opuesta de la MPPDA ante un mismo material antes y después de 1934, es decir, previa y ulteriormente a la implantación (auto)obligatoria de Hollywood de la autocensura mediante la aplicación rigurosa del Código Hays $(1930)^{5}$ y la creación del organismo instaurado para velar por su cumplimiento, la Production Code Administration (PCA).

\footnotetext{
4 The American Film Institute Catalog Database 1893-1970. Recuperado de http://www.afi.com/members/catalog/. Fecha de consulta: 1 de agosto de 2015. A partir de aquí citado como AFI Catalog.

${ }^{5}$ De verdadero nombre Motion Picture Production Code. Tanto la Oficina Hays como el Código se denominaron así por Will Hays, que ocupó la presidencia de la MPPDA desde su creación en 1922 y hasta 1945.
}

(C) Ediciones Universidad de Salamanca / CC BY - NC ND Fonseca, Journal of Communication, n. 12, 2016, pp. 183-204 
Así, el estudio de este caso concreto, nunca antes abordado de forma pormenorizada, constatará que el modus operandi tan alejado de la censura en cada película se asentó directamente sobre razones contextuales de tipo histórico, relacionadas con su poder e influencia, solo conseguidas a raíz de la constitución de la PCA y la figura de Joseph I. Breen como su director ${ }^{6}$.

\section{FuENTES EMPLEAdAS, METOdología Y ESTADO DE LA CUESTIÓN}

Para poner de relieve todas estas cuestiones, hemos considerado atentamente las cinco fuentes principales relacionadas con los objetivos señalados: el relato del siglo XIX; la dramatización; la novela; y los films de 1932 y 1947.

$\mathrm{Al}$ respecto de la historia de Madeleine Smith, se han consultado abundantes documentos, que aparecen recogidos en el epígrafe 7 consagrado a la Bibliografía. También queremos destacar el film británico dirigido por David Lean Madeleine (1950), emplazado en su legítimo escenario de la era victoriana ${ }^{7}$.

Para conocer el entramado dramático de la pieza de Sheldon y Barnes nos hemos servido de las sentencias originales del litigio contra MGM, de libre acceso en la página web del Tribunal Supremo de los Estados Unidos ${ }^{8}$. Asimismo, Blood on the Stage, 1925-1950 (Kabatchnik, 2010) ha sido de gran utilidad. La novela Letty Lynton se ha examinado por medio de una edición traducida a la lengua castellana (Lowndes, 1948).

Cada largometraje se ha estudiado inicialmente por separado, articulándose en los dos casos conforme a dos ejes principales: una primera sección histórica, destinada a documentar la puesta en marcha del proyecto, con especial énfasis en las restricciones de la MPPDA; y una segunda parte consagrada al análisis de las cintas propiamente dichas, donde son examinadas en virtud de discernir las fuentes de las que toman sus dispositivos dramáticos para construir su historia y con objeto de identificar sus similitudes y diferencias. Con posterioridad, tras el estudio individualizado de ambos largometrajes, pasamos a exponer los resultados y conclusiones.

Con relación a la sección inicial de los films, donde se documenta su génesis y la intervención de la Oficina Hays, queremos indicar que se han utilizado primordialmente fuentes coetáneas, muchas veces procedentes de publicaciones cinematográficas especializadas (Film Daily, Motion Picture Daily y Variety). La elección preferente de estos materiales frente a textos de carácter historiográfico se fundamenta en que son los únicos donde se halla este tipo de información expuesta con detalle y de modo veraz, dado que el tema apenas ha sido abordado por fuentes secundarias y menos aún con rigor o profundidad ${ }^{9}$. Este aspecto se acentúa en Letty Lynton, donde el proceso de preproducción y trámites de MGM con la censura para lograr (sin éxito) la adquisición de la obra únicamente figuran en las sentencias judiciales de $1934^{10}$ y $1936^{11}$.

En lo que atañe a los largometrajes, Letty Lynton se halla fuera de la circulación desde 1936. Jamás se ha editado en ningún tipo de soporte y hasta hace muy poco nadie había podido acceder a él (Wal-

\footnotetext{
${ }^{6}$ Breen ejerció de director de la PCA desde 1934 hasta su jubilación en 1954.

${ }^{7}$ El cineasta lo realizó por insistencia de Ann Todd, que entonces era su esposa y acababa de encarnar a Madeleine en una versión teatral londinense -The Rest Is Silence (1944), de Harold Purcell-, pero no utilizó la obra, sino que se documentó de forma exhaustiva de los hechos reales publicados por la prensa durante el juicio (Brownlow, 1996).

${ }^{8}$ Sentencias originales del proceso judicial Sheldon et al. v. Metro-Goldwyn Pictures Corporation et al., United States Federal Goverment, United States Supreme Court. Recuperadas de https://supreme.justia.com/. Fecha de consulta: 5 de agosto de 2015.

${ }^{9}$ Los escasos textos actuales que han contemplado brevemente las películas incurren en numerosos errores. Por ejemplo, Shearer (2010) señala que Stromberg adquirió la pieza teatral en 1944, cuando lo hizo en 1942. Y Decherney (2012) indica que Sheldon fue el autor del guion del largometraje de 1947, que fue realizado en su mayor parte por Ben Hecht, como se verá.

${ }^{10}$ Sheldon v. Metro-Goldwyn-Pictures Corp., 7 F. Supp. 837 (S.D.N.Y. 1934). A partir de aquí citada como Sheldon I.

${ }^{11}$ Sheldon v. Metro-Goldwyn-Pictures Corp., 81 F.2d 49 (2d Cir. 1936). En adelante referida como Sheldon II.
}

(C) Ediciones Universidad de Salamanca / CC BY - NC ND Fonseca, Journal of Communication, n. 12, 2016, pp. 183-204 
ker, 1983; Gutner, 2001; Vieira, 2009). Sin embargo, en el momento de la escritura de este trabajo circula libremente en la web, y esta es la copia que hemos empleado. Sin duda, su sorpresiva aparición, después de casi 80 años, proporciona el marco contextual idóneo para el análisis, al margen de sinopsis preexistentes, que han constituido su único modo de aproximación durante décadas. En cuanto a Dishonored Lady, se ha comercializado en diversos formatos, pero se trata de una cinta poco examinada y conocida.

Por último, queremos recalcar que, aunque los films a menudo han sido mencionados como versiones equivalentes, dichas acotaciones en los textos bibliográficos no pasan de la simple mención y las dos películas nunca han sido estudiadas de manera comparada.

\section{LETTY LYNTON(CLARENCE BROWN, 1932)}

\subsection{LA OFICINA HaYS Y SU DESAUTORIZACIÓN DE LA OBRA DISHONORED $\operatorname{LADY}(1930)$}

Sheldon y Barnes comenzaron a escribir su pieza en torno a $1928^{12}$. Producida por Gilbert Miller y Guthrie McClintic y puesta en escena por este último (Hischak, 2009), se representó por primera vez en enero de 1930 en Rochester, Nueva York ("Inside Stuff-Pictures”, 1932). El 4 de febrero se inauguró en el Empire Theatre de Broadway, con la reputada actriz Katharine Cornell y Fortunio Bonanova a cargo de los papeles principales de Madeleine Cary y Jose Moreno (Sheldon I; Hischak, 2009). En la página inicial de su texto, los dramaturgos escribieron: "Los autores saludan con gratitud a la Srta. Madeleine Smith de Glasgow, cuya conducta en 1857 les sugirió esta obra. En consecuencia, ellos hacen un gesto de amistad y admiración hacia ella a lo largo de los años" (Sheldon I).

Metro-Goldwyn-Mayer enseguida mostró interés y al día siguiente de su estreno neoyorquino Irving Thalberg, vicepresidente y jefe de producción de la compañía, ya tenía el manuscrito (Sheldon I). Lo devolvió el 26 de marzo, expresando su imposibilidad de adquirir los derechos por causa del veto de la Oficina Hays (Sheldon I).

Pese a la prohibición, las negociaciones se prolongaron hasta bien adentrado 1931. En noviembre de 1930 se encargó a los escritores un nuevo tratamiento, desprovisto de las objeciones de la MPPDA. Thalberg lo recibió el 3 de diciembre, pero lo retornó el día 16, argumentando lo mismo que la primera vez (Sheldon I). Aun así, el 14 de abril de 1931 se redactó un contrato de venta por 30.000 \$, sujeto al consentimiento final de la censura (Sheldon I; Sheldon II). El asunto concluyó en junio de 1931, en una reunión donde Hays rehusó levantar su desaprobación (Sheldon I).

Para entonces MGM ya había descubierto la novela inglesa Letty Lynton, lo que explica que no ejerciera mayor presión sobre Hays para obtener su consentimiento. La compra del libro se ultimó el 4 de diciembre por la módica suma de 3.500 \$ (Sheldon I; Vieira, 2009). Al comienzo de la novela, Marie Belloc Lowndes señaló igualmente el origen de su historia: “Aunque muchos lectores adivinarán que los dos personajes principales de LETTY LYNTON han sido sugeridos por un célebre juicio por asesinato celebrado en Escocia, el autor quiere dejar sentado que esta historia es pura ficción" (Lowndes, 1948, p. 5).

En realidad, Thalberg y Stromberg iniciaron la preproducción antes de la adquisición de la narración de Lowndes -entre finales de noviembre y principios de diciembre de 1931 (Sheldon II)-, basándose en los acontecimientos de Glasgow y Dishonored Lady, que había obrado en su poder durante casi dos meses. Con posterioridad, añadieron a su historia elementos puntuales de la novela a fin de re-

\footnotetext{
${ }^{12}$ Sin duda, la muerte de la verdadera Madeleine Smith les sirvió como fuente de inspiración, tal cual con toda probabilidad le sucedió a Lowndes.
} 
frendar su aparición en los créditos y protegerse legalmente. El plagio que se decretó en 1936 estaba más que justificado. Es más, tan consciente era Thalberg de haber copiado ilegítimamente la obra que, ante el temor a una futura demanda por violación del copyright, solicitó a Jason S. Joy y Lamar Trotti, del Studio Relations Committee (SRC) ${ }^{13}$, oficina subsidiaria en Hollywood de la MPPDA, un análisis comparativo detallado entre el guion y la dramatización. Conservado en los archivos de la película de la MPPDA/PCA en la Academy of Motion Picture Arts and Sciences Library (AMPAS Library), señalaba seis puntos de peligrosas semejanzas, a tener en cuenta y/o rectificar ${ }^{14}$ :

1. En los dos textos la heroína tenía romances debido a su necesidad de sexo, no de amor.

2. La ejecución del asesinato era similar.

3. El villano era de Argentina en los dos relatos. (Este aspecto se modificó en el film, donde su origen es simplemente sudamericano. Con todo, comprobaremos que se apunta hacia su residencia fija en Buenos Aires).

4. En la pieza la protagonista era huérfana de madre; en el guion, de padre.

5. En la dramatización un amigo proporcionaba a la heroína la falsa coartada sexual que la exculpaba del crimen; en el guion una coartada idéntica la aportaba su prometido.

6. En la obra su padre cometía perjurio; en el libreto, la madre.

El 11 de enero de 1932 Joy escribió a Hays: "Letty Lynton es con toda la intención y propósito la misma historia que Dishonored Lady" (Vieira, 2009, p. 187). Así pues, Hays sabía que estaba a punto de dar luz verde al mismo argumento que poco antes había proscrito y tachado de obsceno. No obstante, lo autorizó porque estaba enmascarado y portaba otro título.

Joy no fue tan claro con Thalberg y Stromberg sobre las similitudes; les comunicó que podían surgir complicaciones, pero que las diferencias entre los desenlaces eran lo suficiente contundentes como para esquivar una demanda (AFI Catalog): Dishonored Lady tenía un final amargo, donde Madeleine recibía su castigo moral y perdía a su auténtico amor; en el guion Letty conservaba su devoción. La MPPDA dio su beneplácito y la película se filmó desde el 21 de febrero hasta el 28 de marzo de 1932 (Sheldon I).

\subsection{EL FILM Y SUS FUENTES LITERARIAS}

Letty Lynton destaca sobre todo por ser una cinta desinhibida, sin valores morales compensatorios y acorde con la libertad ideológica y sexual del periodo en que se rodó: la era Pre-Code (1930-34), anterior al Código Hays ${ }^{15}$. A este respecto, las primeras escenas inciden de inmediato, y sin ningún tipo de condena, en una vívida descripción de la promiscuidad de la protagonista, que es presentada bailando en un club nocturno de Montevideo, Uruguay, acompañada por el sudamericano Emile Renaul (Nils Asther) (Figura 4). Rica heredera de Nueva York, Letty ha abandonado los Estados Unidos para divertirse y tener amoríos. Tanto la libre conducta sexual de Letty como el origen de ambos proceden de Dishonored Lady y no poseen ningún tipo de analogía ni con los acontecimientos del siglo XIX ni con la novela. Madeleine Smith, como ya se ha dicho, era de Glasgow y en la novela Letty (en adelante Lettice) es inglesa, de la ficticia localidad de Thark. Sus equivalentes, L'Angelier y Axel Ekebon, tenían nacionalidad francesa y anglo-sueca, respectivamente.

\footnotetext{
${ }^{13}$ En el verano de 1934 el SRC sería transformado en la PCA.

${ }^{14}$ Información parcialmente extraída de AFI Catalog.

${ }^{15}$ Basta con señalar que ostentó los títulos provisionales durante el rodaje de Redeemed y Promiscuous (AFI Catalog).

(C) Ediciones Universidad de Salamanca / CC BY - NC ND Fonseca, Journal of Communication, n. 12, 2016, pp. 183-204
} 
Figura 4. Fotografía publicitaria de Letty Lynton (1932).

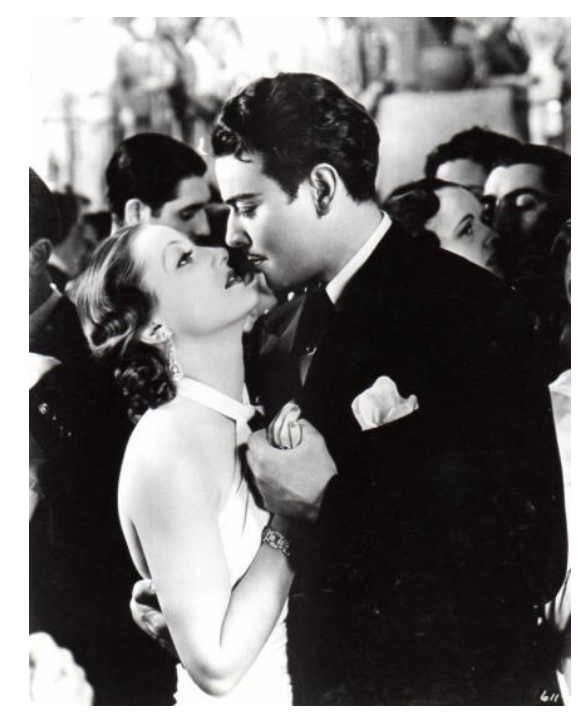

Advertimos, sin embargo, una significativa alteración en la posición económica de Emile, que ha sido transformado en un individuo de gran fortuna, algo en lo que Letty Lynton se aleja de los acontecimientos de 1857, así como de la dramatización y la novela, que conservan intactos los designios y la estratificación social de L'Angelier. En la pieza teatral Moreno es bailarín en un cabaret y en la historia de Lowndes Ekebon más bien haraganea, y ambos, igualmente, pretenden mejorar su posición económica y social a través de sus relaciones con la heroína. No obstante, en esto el film de MGM coincide exclusivamente y de modo anómalo con el de 1947, donde el supuesto sucedáneo de L'Angelier, Felix Courtland (John Loder), es multimillonario y no persigue a la protagonista para elevar su estatus ni por dinero.

Lo que Letty siente por Emile no es amor, sino sexo; una fuerte dependencia que no puede controlar y que el sudamericano conoce. Las cartas no tardan en aparecer. Todas las escenas vinculadas con las misivas se derivan de los hechos reales de Glasgow y de la novela británica, porque Sheldon y Barnes las eliminaron de su pieza. Letty comunica a Emile que piensa abandonarle, y él responde: "Has huido cuatro veces en estos tres meses. En tres, cuatro o cinco días me escribes y me dices sencillamente que no puedes vivir sin mí”. A continuación, se apunta el alto y explícito contenido erótico de las cartas, dado que Letty no puede dar por concluida su relación con Emile dejándolas atrás. Para evitar que este perciba su interés en recuperarlas y proporcionarle la idea de utilizarlas como medio de coacción y chantaje, las menciona de manera distraída: "Emile, ¿todavía tienes las cartas que te escribí?”. "Sí, en Buenos Aires, ¿por qué?”. Este es el comentario, antes indicado, que señala Argentina como el lugar del que es oriundo, matiz incorporado, otra vez, ilícitamente de la obra teatral. Podemos suponer que Letty le cree, puesto que al día siguiente se embarca en un transatlántico con destino a Nueva York. Mas Emile le ha mentido; siempre lleva las cartas consigo.

La relación de la verdadera Madeleine Smith y L'Angelier emerge cuando Emile expresa: "No me puedes abandonar así. Me perteneces. Y a nadie más... Nunca me abandonarás...". Tal como le sucediera a aquel, no está dispuesto a ser rechazado. Este afán de dominación del personaje figura en la dramatización, pero no en la novela, donde Ekebon, pese a ser un arribista y un chantajista, trata a 
Lettice con veneración y admiración, en gran parte por su elevadísimo estatus social y pertenencia a las clases nobles de Inglaterra.

El apetito sexual de Letty se patentiza cuando Emile se le aproxima de forma íntima. Aunque le odia y ha planeado su fuga, es incapaz de resistirse a sus caricias. Los dos se besan, tras lo cual se produce una elipsis marcada por un sugerente fundido en negro, que alude, inequívocamente, a la relación sexual que acontece en off.

A la mañana siguiente, a punto de subir al barco, Letty se ríe a carcajadas de Emile. La atrevida sexualidad del film se manifiesta sin tapujos por el comentario de su criada Miranda (Louise Closser Hale): "Duerme como un rinoceronte". Por si el implícito fundido en negro anterior hubiera escapado a algún espectador, se expone así de forma clara que Letty se ha acostado con él, ha recogido a hurtadillas y le ha dejado durmiendo. Avanzada la cinta, el propio Emile lo confirmará al reprocharle: "Me estás haciendo quedar como un pelele. Cuando me despierto, te has ido". Al mismo tiempo, de lo expuesto se deduce que Letty ha cohabitado con él durante los tres meses que ha estado en Montevideo. Por otro lado, que viaje acompañada de Miranda es un motivo tomado de la novela, donde Lettice tiene en su antigua nodriza, Squelchy, a su persona de mayor confianza.

Las partes que se desarrollan a bordo del transatlántico son genuinas de la cinta. Son también las más rutinarias y románticas, concebidas para satisfacer a los fans del star system de Metro-GoldwynMayer, ya que durante la travesía Letty conoce al increíblemente rico Jerry Darrow (Montgomery) y hacia el final del trayecto se comprometen. Todos los relatos comparten que el futuro desposado de la heroína es un hombre de gran posición y riqueza, excepto la película de 1947. Ahora bien, solo en la obra teatral, el film de 1932 y la producción independiente de Stromberg ella está realmente enamorada de él. Dicha coincidencia de los largometrajes se deriva del plagio efectuado por la cinta de MGM de la dramatización.

La protagonista se presenta ante Jerry como sigue: "Mi padre está muerto. Era Alexander Lynton, Industrias Químicas Lynton, Long Island, Nueva York". Salvo por la ciudad, este es otro detalle que denota la huella puntual de la novela, donde el patrimonio de la familia proviene de tales industrias de Sir John Lynton, que, empero, sigue vivo, al igual que Lady Alice Lynton.

En cambio, la causa del fallecimiento del padre proviene de Dishonored Lady. Letty le dice a Jerry: "Procuro evitar las Navidades en casa porque a mi padre le dispararon por esa época del año". "¿Le dispararon?", pregunta él. Y ella comenta: "Verá, el marido de la dama perdió su tren o algo así, y las campanas navideñas le recuerdan a mi madre ciertas cosas, así que procuramos eludir la Navidad". Aunque las frases son muy rápidas y todo está bastante velado, el mensaje es axiomático: el padre de Letty era un mujeriego incorregible, que engañaba sistemáticamente a su esposa. En una de tantas, un marido regresó antes de lo previsto, los pilló in fraganti y le mató de un disparo. Este fue uno de muchos argumentos que esgrimió el juez Learned Hand en 1936 para decretar el plagio, quien escribió: "La desobediencia de cada heroína se sugiere como una disposición hereditaria; cada una ha tenido un padre descarriado involucrado en un escándalo" (Sheldon II). Efectivamente, pues en la pieza teatral el padre de Madeleine mató de un disparó al amante de su mujer, y la cinta lo invierte. Asimismo, el largometraje insistirá en la lascivia de Letty como un rasgo heredado de su progenitor, siendo este otro de los pocos nexos que comparten ambos films de 1932 y 1947.

La explicación de Letty de por qué está fuera de su casa en Navidad no se atiene a la verdad. Ella le oculta a Jerry deliberadamente a qué ha dedicado su tiempo en Sudamérica, así como sus relaciones prematrimoniales con Emile. Cuando el barco atraca en Nueva York, descubre para su horror que Emile la ha seguido tomando unos de los primeros vuelos comerciales (Figura 5). Aunque no sin 
dificultades, consigue darle esquinazo y salir del muelle sin que su prometido coincida con su ex amante.

Figura 5. Fotografía publicitaria de Letty Lynton (1932).

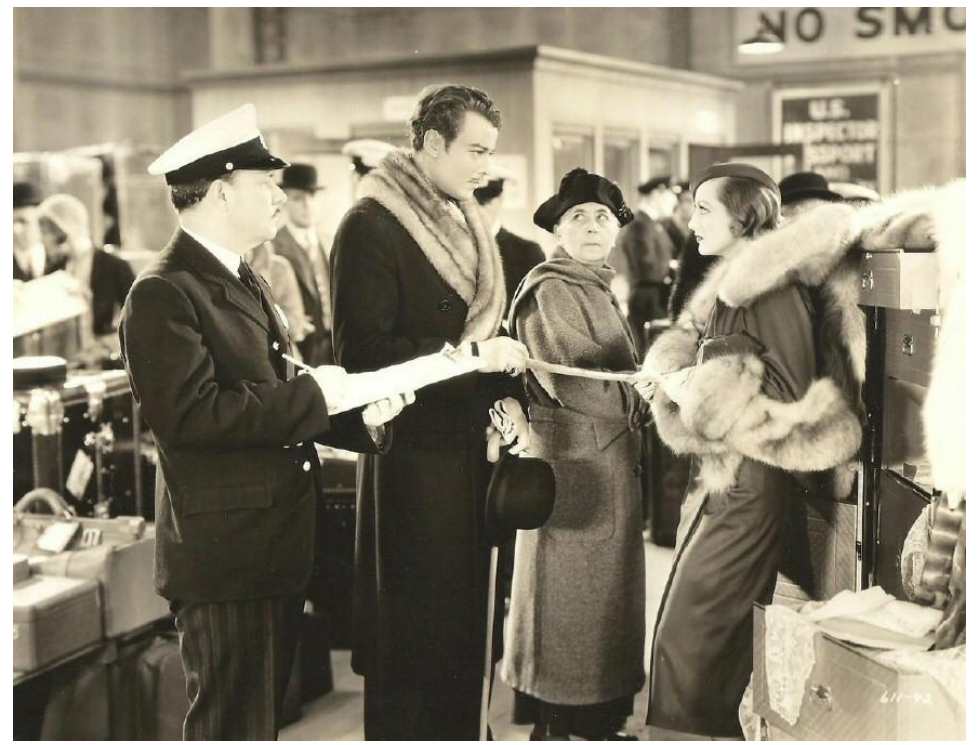

En lo que respecta al trabajo de dirección, Letty Lynton destaca sobre todo por el tremendo cuidado desplegado por el cineasta Clarence Brown en la composición pictórica de los encuadres, de acusada y buscada simetría, y por su depurada fotografía. Es una producción de Clase A, de la que se entrevé una excelente factura, a pesar de la deficiente calidad de la copia disponible en la web ${ }^{16}$. La profundidad de campo es una constante, así como la organización de las acciones dentro del campo visual en varios niveles espaciales, muchas veces con elementos de reencuadre dentro del encuadre para reasentar desde dentro los dispositivos que integran el plano ${ }^{17}$. Estos rasgos compositivos están presentes en numerosas escenas, entre las que sobresale la subsiguiente visita de Emile a la mansión de Letty, donde profiere sus amenazas. Ambos constan situados al fondo de la imagen, en el salón, mientras la madre de Letty (May Robson) ve y escucha lo que ocurre desde el primer término, de espaldas a la cámara, y todo está a foco nítido.

Enterado de su compromiso matrimonial por los periódicos y enfurecido por lo ocurrido en la aduana, Emile no da por terminada su relación e insiste en que van a volver juntos a Sudamérica. Cuando Letty se niega en rotundo y le dice que llamará a la policía si no se va, él la amenaza con divulgar sus cartas: "Si antes de las 20:00 h. no estás en mi hotel, mañana leerás de tu propio puño y letra que no puedes vivir sin Emile Renaul". "No hay amor para ti, salvo el mío", es su última frase.

\footnotetext{
${ }^{16}$ De hecho, su impecable calidad fotográfica fue específicamente subrayada en la época del estreno por el New York Times (Hall, 1932).

${ }^{17}$ Clarence Brown comenzó su carrera cinematográfica en la década de 1910 con el reputado director pictorialista de origen francés Maurice Tourneur, de quien aprendió el uso del enfoque nítido. Por ello, utilizó la fotografía con profundidad de campo de forma creativa a lo largo de toda su filmografía, silente y sonora. Sus películas contienen innovaciones importantes con lentes de gran angular previamente a las prácticas de Gregg Toland en los años 30 con William Wyler, John Ford y Howard Hawks y con anterioridad a Citizen Kane (Ciudadano Kane, 1941), de Orson Welles y con Toland a cargo de la fotografía. Para un desarrollo de este tema, consúltese Guiralt Gomar, 2012, pp. 934-944, 1647-1648.
} 
Aunque ha sido testigo de lo ocurrido, la madre de Letty no le presta su apoyo. Que la Sra. Lynton sea fría e incomprensiva puede inferirse como un rasgo oriundo de la novela, donde Lady Lynton tan solo está preocupada por las apariencias y la vida social. Sin embargo, el film cambia esta concepción del personaje y atribuye su distanciamiento de Letty a los desengaños sufridos por las infidelidades de su esposo. Dado que la Sra. Lynton está convencida de que Letty es como su padre -infiel por naturaleza-, le ha retirado su cariño y no la cree cuando ella le confiesa que se ha enamorado por primera vez en su vida.

La protagonista se expone al deshonor y a la disolución de su unión con Jerry, por lo que decide conseguir las cartas o acabar con su vida. Con tal propósito, localiza una botella de estricnina en la casa. Tanto la clase de veneno como el lugar donde es hallado emanan de Dishonored Lady y son diferentes en los otros dos relatos. Madeleine Smith compró arsénico en varias farmacias de Glasgow y Lettice lo obtuvo de las industrias químicas de su progenitor. El suicidio, en cambio, parece inspirado por la novela; la verdadera Madeleine Smith jamás pensó en suicidarse, como tampoco Madeleine Cary en la obra teatral, pero en la novela Lettice, antes de resolver que debía asesinar a Ekebon, sí consideró vagamente la posibilidad.

El pasaje más notable y sobrecogedor del largometraje lo constituye el envenenamiento en la habitación de Emile en el hotel. Aquí la película cambia bruscamente de género y pasa del melodrama romántico al cine de tipo criminal. Letty le suplica que le devuelva sus cartas, pero él la ignora. Convencida de que no las va a recuperar, vierte la estricnina en su copa de champán. Cuando le dice que está enamorada de Jerry y se arrepiente de cada minuto miserable que pasó a su lado, Emile la trata con violencia y la golpea brutalmente, un contenido que proviene únicamente de la pieza teatral. Tras propinarle varios puñetazos, le recrimina los cientos de hombres que han pasado por su vida y pretende llevarla al dormitorio. Letty prefiere morir antes que acostarse con Emile y pasar el resto de su vida con él, por lo que se dispone a ingerir su copa de champán envenenada. Mas es Emile quien la coge y bebe de ella (Figura 6). Letty no solo no le detiene, sino que cuando él intenta alcanzar el teléfono para pedir ayuda, se lo impide.

Figura 6. Fotografía publicitaria de Letty Lynton (1932).

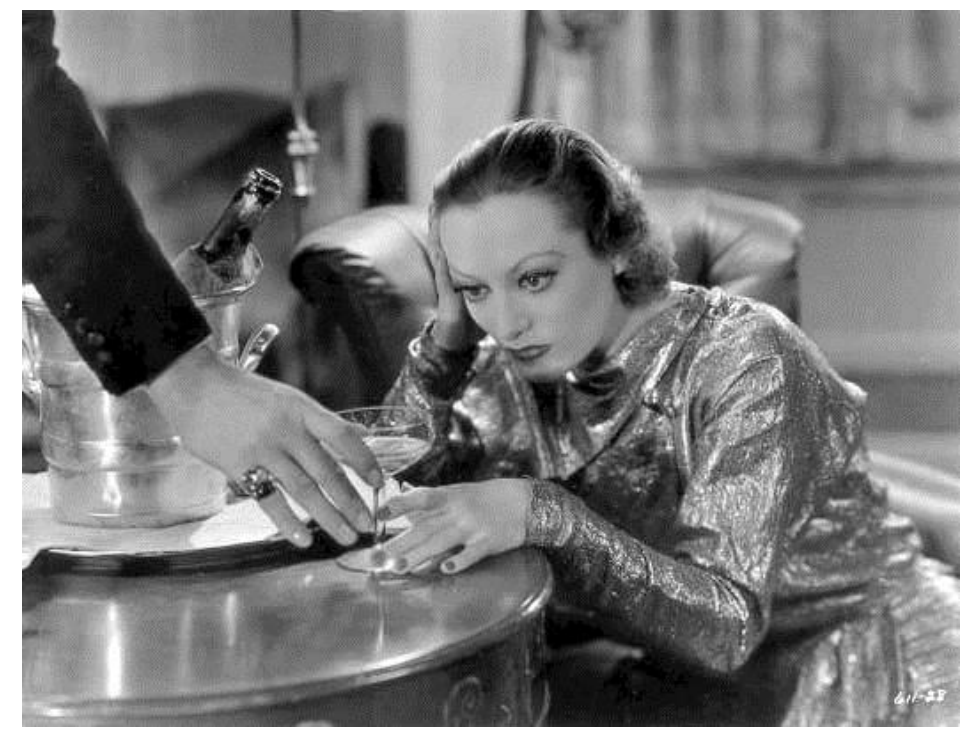


La secuencia destaca por su puesta en escena al servicio de la dramaturgia, provista de iluminación de alto contraste y fotografía de enfoque en profundidad. Brown utiliza muy hábilmente las lentes de corta distancia focal cuando, con posterioridad a la muerte Emile, un camarero entra en la habitación y Letty se esconde tras una cortina. Ella permanece inmóvil en el primer término, mientras por detrás el botones realiza varias acciones; un tipo de planificación que incrementa notablemente la tensión emocional ante la posibilidad de vaya a ser descubierta en cualquier momento. Finalmente, el camarero cree que Emile está inconsciente por causa del licor y se va. Letty borra las huellas de su presencia y logra huir sin ser vista.

Al día siguiente, en la mansión de sus futuros suegros, es arrestada y llevada a comisaria. Durante el interrogatorio al que la somete el fiscal del distrito (Lewis Stone) salen a relucir las cartas, que Emile guardaba en una caja de seguridad del hotel, así como el resguardo de la aduana, que ella le entregó en el muelle, y sus chanclos, que olvidó en el hotel (Figura 7). Justo cuando está a punto de desmoronarse y confesar, interviene Jerry, quien miente, dice estar al corriente de todo y asegura que él mismo recogió a Letty en el vestíbulo del hotel después de su entrevista con Emile -a una hora que es anterior a la de su muerte. Luego asegura que ella pasó la noche con él. La Sra. Lynton y Miranda confirman su testimonio. Aunque el fiscal no les cree, no le queda otro remedio que dejar a Letty en libertad. Por consiguiente, la protagonista no es juzgada en los tribunales, siendo este un distintivo exclusivo de la película.

Figura 7. Fotografía publicitaria de Letty Lynton (1932).

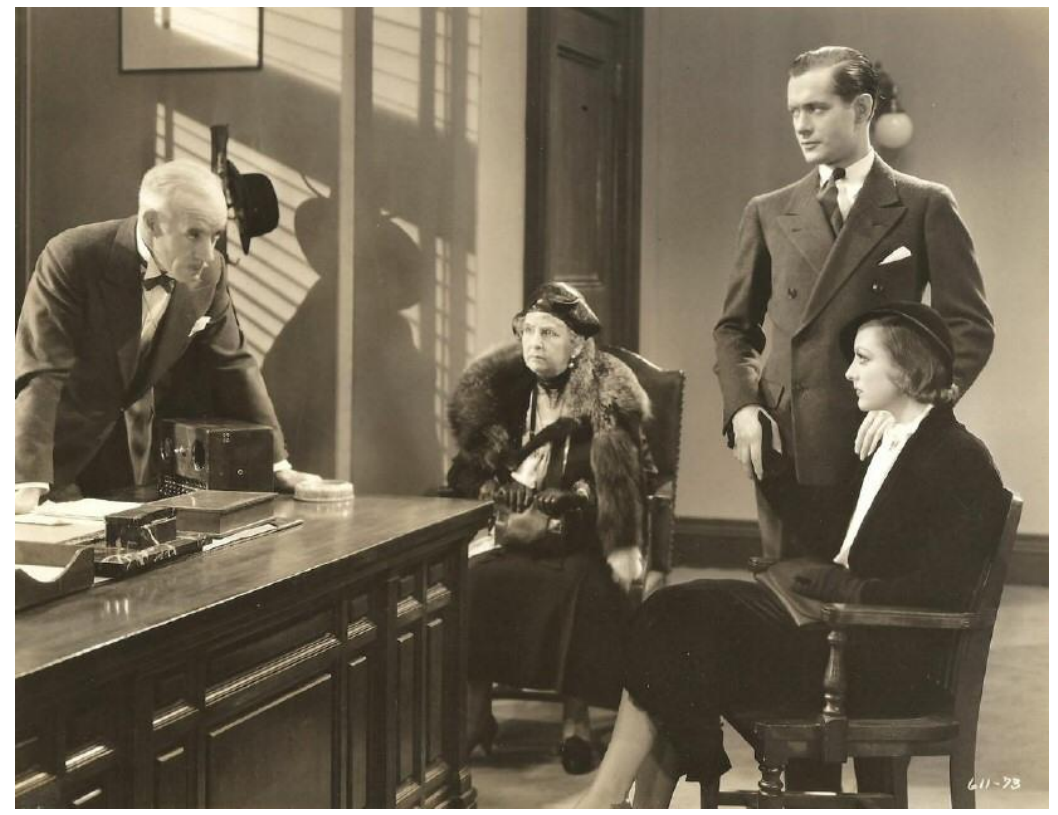

El desenlace es verdaderamente lo más subversivo. Convencida de que su relación con Jerry ha llegado a su fin, Letty se despide: "Espero que sepas por qué lo hice”, le dice, confesándole, por lo tanto, que cometió el crimen y es una asesina. Pero a Jerry no le importa, sigue queriendo casarse con ella y el relato acaba felizmente. 
Como avanzábamos, el film se sitúa en plena conexión con la producción hollywoodiense de la era Pre-Code, pero, aun así, es increíblemente osado incluso para el cine anterior a la PCA. En realidad, lo que resulta inaudito y desconcertante (aunque no inexplicable) es que la Oficina Hays objetara la pieza Dishonored Lady y no la trama que terminó desarrollando Letty Lynton. La película no muestra ningún tipo de desaprobación o condena moral hacia los actos - sexuales y homicidas- de la protagonista. Ella es totalmente exculpada, no recibe ningún castigo y su prometido la perdona sin dudarlo. De hecho, el largometraje tuvo problemas de distribución en algunos países, como Italia y Suiza (AFI Catalog), y fue prohibido en Inglaterra, precisamente porque justificaba el homicidio (Walker, 1983; Vieira, 1999). En efecto, transmite el mensaje de que Emile merecía morir, porque era un individuo despreciable, posesivo, brutal y un chantajista, mientras que a Letty se le da la oportunidad de comenzar una nueva vida.

\section{Dishonored LADY (ROBERT STEVENSON, 1947)}

\subsection{LA PCA Y SUS MÚLTIPLES IMPOSICIONES SOBRE LA HISTORIA Y EL GUION}

Como ya expresamos, Hunt Stromberg adquirió los derechos de la obra de Sheldon y Barnes en junio de 1942. Aunque la PCA dio su consentimiento para la adquisición del material ("Much Litigated", 1942), sus interferencias no tardaron en llegar y el rodaje quedó indefinidamente pospuesto. No se retomó hasta enero de 1944, momento en que el productor contrató a André de Toth como director ("Coast Flashes", 1944).

A comienzos de verano, Stromberg entregó a Joseph I. Breen un primer borrador del libreto, firmado por Sophie Treadwell, que el censor objetó desde todos los frentes. En un memorándum fechado el 28 de julio, conservado en los archivos del film de la MPPDA/PCA (AMPAS Library), este lo calificó de inadmisible porque la protagonista era una muchacha de conducta sexual obscena y perdida que tenía aventuras amorosas en Méjico y Nueva York, primero con un bailarín de cabaret y después con un soldado (AFI Catalog). Y añadió: "La historia básica [...] es total y completamente inaceptable bajo las cláusulas del Código, porque esta es una historia de repugnante sexo ilícito, con insuficientes valores morales compensatorios. Además, es la historia de una asesina que no recibe su castigo" (Barton, 2010, p. 161). Entre sus numerosas exigencias, impuso que varios personajes condenasen la vida inmoral de Madeleine y recibiese su merecido sufrimiento en la conclusión.

Convencido de que pronto lograría satisfacer al censor, a mediados de agosto Stromberg firmó contrato con la estrella mejicana Pedro Armendáriz para el papel de Jose Moreno (transformado de argentino en mejicano) y fijó la producción para octubre (Bell, 1944). Poco después, reclutó al reputado guionista Ben Hecht para un nuevo desarrollo argumental. El 1 de noviembre Motion Picture Daily anunciaba que el rodaje no comenzaría hasta enero de 1945 ("Studios Limit”, 1944) y el 13 de diciembre la misma publicación notificaba que se postergaba a febrero ("Stromberg Back", 1944).

El productor no recibió una respuesta de Breen hasta el 25 de abril de 1945. Aunque el guión incluía ahora numerosas correcciones, entre ellas la inocencia de Madeleine, el director de la PCA lo impugnó porque era la exposición de la vida de una ninfómana (AFI Catalog) y se intuía un final feliz para la heroína:

Como se lee, esta es la historia de una joven de la que se sugiere que es una especie de ninfómana, y que, cuando se enamora de un muchacho bueno y decente, quiere finalizar por completo sus relaciones con su antiguo amor, intenta asesinar al ex amante, falla y se ve involucrada en un juicio que finalmente establece el hecho de que no es la asesina, se le 
permite irse de rositas, con la sugerencia de que finalmente se reunirá con el hombre decente. La historia básica, por supuesto, no puede ser aprobada (Barton, 2010, p. 162).

A principios de junio, Stromberg entregó a Breen otro tratamiento que eliminaba el intento de asesinato premeditado de Madeleine y le adjudicaba un final trágico. En esta versión, al conocer a David, el aludido por Breen como "muchacho bueno y decente", Madeleine decidía romper su relación con Moreno - como en el relato del siglo XIX, la pieza teatral y Letty Lynton. Pero Moreno ejercía una fuerte dominación sobre ella -como en la obra y Letty Lynton- y ambos sostenían una noche de sórdida pasión -tal cual sucede en la obra, no en el film de 1932, aunque ese era el propósito de Emile en el hotel. A la mañana siguiente, Madeleine se despertaba degradada, y cuando Moreno despreciaba su amor por David, le disparaba y creía haberle matado. Con posterioridad, confesaba todo al juez sin ánimo de sobrevivir. No obstante, su padre investigaba y descubría que era inocente. Tras su absolución, se daba cuenta de que no era digna de David y se apartaba de su camino (AFI Catalog). Breen volvió a rechazar esta concepción, dado que la heroína sostenía un tercer y tórrido romance en Nueva York con un individuo llamado Felix Courtland. Asimismo, objetó la noche de sórdida pasión, la descripción de la disoluta sexualidad de Madeleine y sus desagradables antecedentes familiares.

Entretanto, en julio Stromberg se asoció con Hedy Lamarr y Jack Chertok para llevar a cabo dos films protagonizados por la actriz y producidos por los tres bajo las siglas de Mars Film Corp. A la espera del nuevo libreto de Dishonored Lady, se acordó que Strange Woman (La extraña mujer, Edgar Ulmer, 1946) se rodaría antes ${ }^{18}$.

A finales de enero de 1946, Stromberg vendía el contrato de Armendáriz, puesto que Moreno había desaparecido del argumento (“Armendariz”, 1946). Al eliminar al arribista, interesado y chantajista Moreno, Dishonored Lady quedó desprovista del equivalente de L'Angelier de 1857, Ekebon en la novela y Emile Renaul en Letty Lynton, lo que constituyó un gran alejamiento de los demás relatos.

Pese a los drásticos cambios, en una fecha tan tardía como el 25 de abril Breen exigía más modificaciones y declaraba que el guion seguía siendo inaceptable por la presencia de sexo gratuito y referencias a los secretos familiares de Madeleine (AFI Catalog). Un enfadado Ben Hecht se negó a continuar y ordenó que su nombre fuese retirado de la película. Le sustituyó Edmund H. North, que recibió la acreditación en solitario por el guion.

Stromberg no podía retardar más la producción, que en total se había demorado más de dos años, y posiblemente ello indujo a Breen a autorizar el rodaje, que comenzó a principios de mayo y concluyó a finales de julio de 1946 (AFI Catalog).

\subsection{EL FILM Y SUS FUENTES LITERARIAS}

Desde el comienzo la música sinuosa de suspense, la iluminación nocturna y contrastada, el ambiente urbano y las calles llenas de humedad señalan que nos encontramos ante un tipo muy distinto de película, un melodrama criminal con tintes de género negro y una fuerte vertiente psicoanalítica, tan en boga en los films noir (y otros) de los años 40, como The Woman in the Window (La mujer del cuadro, Fritz Lang, 1944), The Locket (La buella de un recuerdo, John Brahm, 1946) y Secret Beyond the Door (Secreto tras la puerta, Fritz Lang, 1948).

\footnotetext{
${ }_{18}$ Ambos se filmaron en los Samuel Goldwyn Studios, fueron distribuidos por United Artists y ostentaron el emblema $A$ Hunt Stromberg Production.
}

(C) Ediciones Universidad de Salamanca / CC BY - NC ND Fonseca, Journal of Communication, n. 12, 2016, pp. 183-204 
En una carretera oscura por la noche dos policías comentan que han visto algo extraño: una mujer guapa y sola, paralizada, dentro de un coche. Se desplazan hasta allí y se presenta a la protagonista, Madeleine Damien, que se muestra completamente ausente, incapaz de articular palabra (Figura 8).

Figura 8. Fotograma de Dishonored Lady (1947).

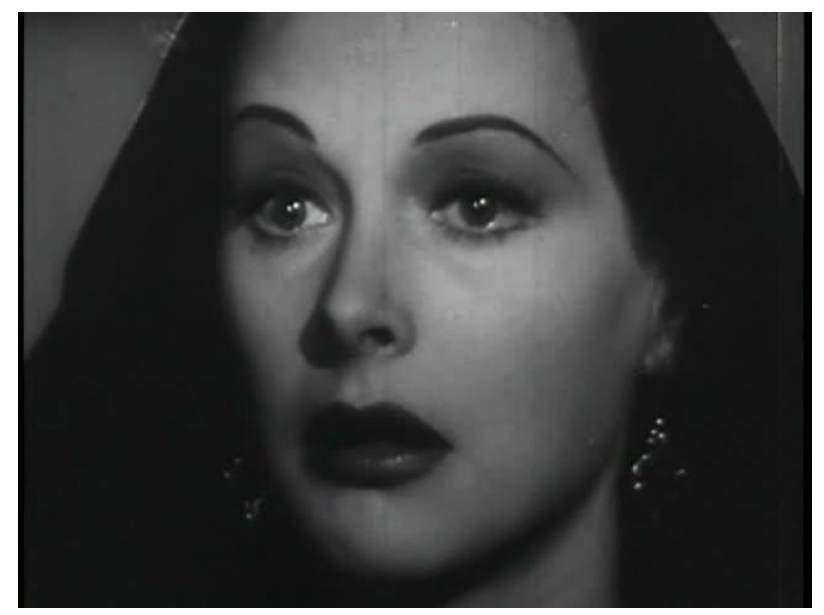

De pronto, arranca el auto a toda velocidad con la clara intención de suicidarse. La casualidad, a la que es tan dada el melodrama, propicia que estrelle su coche justo en la casa de un médico que además es psiquiatra, el Dr. Caleb (Morris Carnovsky). En esta primera sesión de psicoanálisis el doctor se pronuncia sobre su estado mental: "A muchas mujeres les falta valor para enfrentarse a sí mismas, así que buscan una escapatoria yendo de emoción en emoción” (Figura 9). Este es el primer indicio que se proporciona de que su vida es una vorágine de sensaciones vacías.

Figura 9. Fotograma de Dishonored Lady (1947).

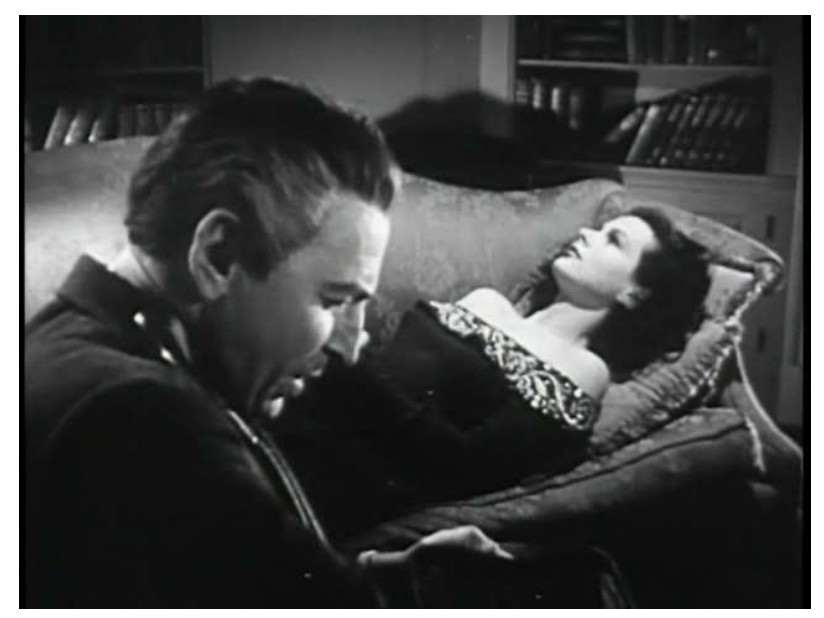


De acuerdo con Lamarr (1968, p. 167), una de las primeras transformaciones fue otorgar "[...] a la Dishonored Lady un toque de categoría so capa de serio interés en el arte"19. En efecto, Madeleine es directora de arte de la revista Boulevard en Nueva York, donde dirige su propio departamento, mientras que ninguna de las heroínas de los otros relatos trabajaba o tenía inquietudes artísticas.

Ahora bien, respondiendo a las demandas ultraconservadoras de la PCA, el film utiliza la condición de Madeleine de career woman ${ }^{20}$ para afirmar su inestabilidad emocional. Ella es profesional, independiente y con poder adquisitivo, pero es infeliz, porque no ocupa el lugar que le corresponde en la sociedad: esposa y madre. En contra de su condición natural, actúa como un hombre en un mundo de hombres (esto explica también su agitada vida sexual; no es espacio adecuado para la mujer). La cinta indica que Madeleine está desquiciada, toma pastillas para dormir y quiere suicidarse porque lleva una vida totalmente equivocada. Esta es la idea constante que se dirige una y otra vez al espectador, y en especial a la audiencia femenina, a lo largo de todo el metraje.

A este respecto, resulta oportuno registrar que el cine clásico de Hollywood posterior a la autocensura de 1934 ofreció pocos retratos de altas ejecutivas o career women, y cuando lo hizo estas aparecieron bajo los mismos parámetros codificados, donde Madeleine encaja a la perfección. Las mujeres que ostentaban estos puestos solo podían hacerlo en profesiones "femeninas". Por ello, encontramos un buen surtido de directoras o editoras de revistas de moda, tal como sucede en Laura (Laura, Otto Preminger, 1944), Lady in the Dark. (Una mujer en la penumbra, Mitchell Leisen, 1944) y There's Always Tomorrow (Siempre hay un mañana, Douglas Sirk, 1956). Otro ejemplo: en To Each His Own (Vida intima de Julia Norris, Mitchell Leisen, 1946) la protagonista es una magnate de la industria de los cosméticos. Dotarlas de un carácter agrio, inestable o neurótico -debido al trabajo y la tragedia que supone haber tenido que renunciar al matrimonio y a la maternidad- es otro habitual. En este sentido, Madeleine presenta enormes similitudes con la heroína de Lady in the Dark, pues comparten profesión y terminarán sometiéndose al psicoanálisis para solucionar sus problemas. Finalmente, se encontrarán a sí mismas al establecerse en los roles habituales que la sociedad adjudica a la mujer, algo que conseguirán solo cuando abandonen su trabajo y su independencia económica en favor del matrimonio.

Una secuencia posterior nos muestra cómo Madeleine se enfrenta a su jefe y a varios colegas de trabajo por causa de un artículo que ha rehusado publicar sobre un acaudalado joyero llamado Felix Courtland. La escena sirve para exponer su eficiencia, su autoridad frente a los varones que la rodean y su integridad profesional al no doblegarse ante los deseos de un multimillonario.

Esa misma noche conocerá al aludido Courtland (Figura 10). Gran parte de los rasgos del suprimido Moreno se incorporaron al personaje, que, en verdad, está lejos de la vileza de L'Angelier, Moreno, Ekebon o Renaul; como mucho se le puede achacar el ser insistente.

Tras ser presentados en un club nocturno, Madeleine se marcha con él a su mansión. Allí repara en un cuadro pintado por su progenitor. Conforme a las exigencias de Breen, este también se eliminó, pero no las referencias turbias a su persona. La mujer del retrato era la madre de Courtland y llegó a estar tan fascinada con el artista que su marido lo echó de casa. Se comunica así que el padre de Madeleine, como el de Letty, era un mujeriego. Si el largometraje de MGM atribuía la lujuria de la heroína a un rasgo heredado de su antecesor, Dishonored Lady va más allá al señalar que Madeleine es un calco de él en todo: su pasión por el arte, su lascivia y sus impulsos suicidas (se sabrá después) proceden de él, y de ahí proviene su desgracia. Cuando Courtland le dice que sus ojos reflejan desesperación y están

\footnotetext{
${ }^{19}$ Ambas alteraciones, el psicoanálisis y la inclinación por el arte, parecen obra suya, a juzgar por el contenido de su autobiografía.

${ }^{20}$ Diferente del concepto de working girl, que en la era clásica de Hollywood se aplicaba a empleos de baja categoría: camareras, bailarinas, trabajadoras de fábrica, dependientas, etc.
} 
llenos de sombras, cede a sus avances y se besan. Como en Letty Lynton, la secuencia culmina con una elipsis, señalizada visualmente por un fundido en negro, que denota la relación sexual que sobreviene fuera de la pantalla.

Figura 10. Fotograma de Dishonored Lady (1947).

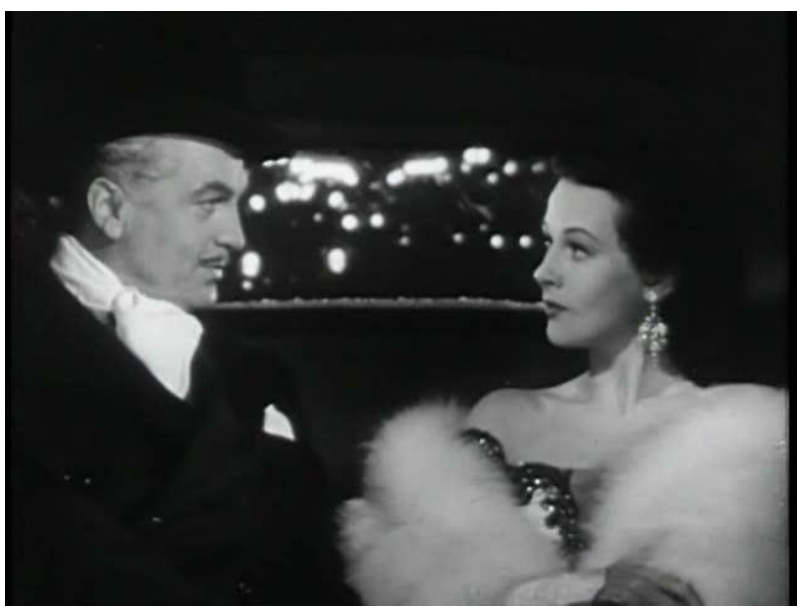

Las exigencias del censor de que determinados personajes condenasen a Madeleine constan por doquier. Primero mediante su secretaria, al día siguiente en la oficina: "He ganado la apuesta, tiene novio nuevo... Hoy uno, mañana otro. Personalmente, no comprendo cómo le gusta eso", le dice a una telefonista. Después, su compañero Jack Garet (William Lundigan) arremete contra ella: “Por qué no reconoces cómo eres? Todos lo saben. Un romance detrás de otro, toda tu vida será siempre igual".

La turbación que siente por los comentarios que cuestionan su moralidad la conducen a visitar al psiquiatra. La voz del censor emerge a través del Dr. Caleb, quien la juzga con vehemencia por su comportamiento libidinoso. Cuando compara su ninfomanía (no referida directamente) con la conducta adictiva de un alcohólico o un drogadicto, ella le dice que la está insultando, y él responde: "Ha estado insultándose a sí misma, insultando su cuerpo y su alma". Como era de esperar, lo primero que le dice el psiquiatra que debe hacer para ser feliz es dejar su trabajo.

La escena en que Madeleine recoge sus pertenencias en la oficina posee especial interés, ya que en ella Garet la amenaza con desvelar a su jefe su romance con el multimillonario si no le entrega 5.000 \$. (La trama había revelado que ella también sostenía una relación amorosa con su jefe). Y este conato de extorsión, ni siquiera perpetrado por el supuesto villano Courtland, sino por un personaje secundario, es lo único que quedó en Dishonored Lady del chantaje original de L'Angelier a Madeleine Smith en 1857.

Su nueva vida en un modesto apartamento de Greenwich Village con aspiraciones de dedicarse a la pintura y una identidad falsa -Madeleine Dixon- no figura en ninguno de los otros relatos. En este aspecto, la cinta incurre en una ostensible contradicción, pues se indica que Madeleine pretende crearse una existencia distinta y, sin embargo, se convierte en pintora, como su progenitor, de cuya influencia supuestamente quiere escapar. 
En su nuevo edificio conoce al joven y apuesto Dr. David Cousins (Dennis O’Keefe) (Figura 11) y, como las protagonistas de la dramatización y del film de MGM, se enamora profundamente de él. No obstante, a diferencia de los prometidos de las otras heroínas, este es un hombre extremadamente pobre, que subsiste mediante una beca de investigación en patología.

Figura 11. Fotograma de Dishonored Lady (1947).

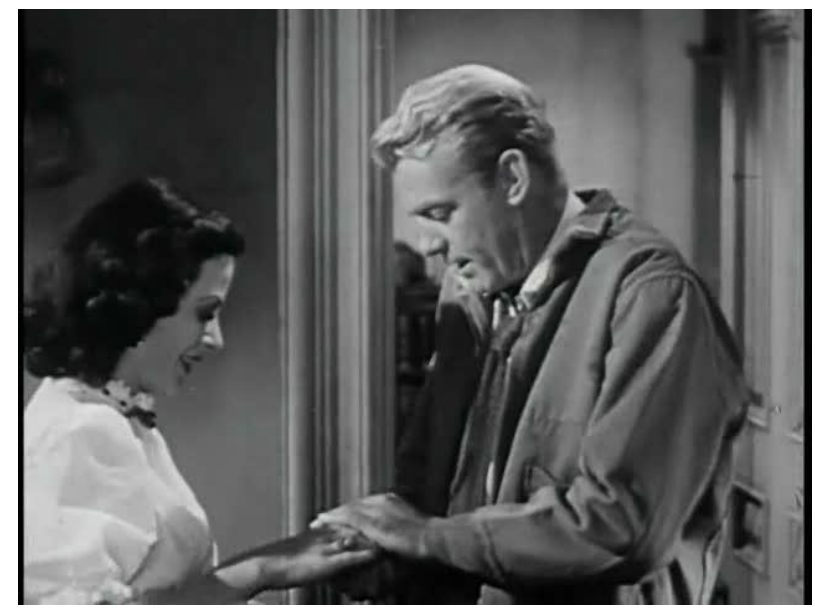

Al igual que Letty, Madeleine le oculta su oscuro pasado y acepta su proposición de matrimonio. Justo después de esta escena, entra en su apartamento y descubre en su interior a Courtland. En contraposición a L’Angelier, Moreno y Renaul, no la amenaza y sí da por finalizada su aventura: "Si alguna vez me necesita, hágamelo saber...”. Otra muestra de que el personaje carece de la mezquindad de los otros la proporciona su encuentro posterior con Madeleine y David en el aeropuerto: no la deja en evidencia, finge formalidad y la llama por su nombre falso: "Srta. Dixon".

En ausencia de David, Madeleine se reúne con sus amigos de la revista y bebe más de la cuenta. Destaca aquí la excelente actuación de Lamarr, una actriz que con frecuencia ha sido tildada de inexpresiva y estática (Moix, 1996). Su estado de embriaguez es representado de forma que logra transmitir a la perfección las sensaciones requeridas en la audiencia; cuando se tambalea en la acera del exterior del local la situación se vuelve sumamente incómoda, manifiesta su indefensión y anuncia el peligro que se avecina. En efecto, porque hasta allí llega Courtland, que la introduce en su coche y la lleva hasta su mansión, una escena que supone una repetición de su encuentro inicial. Mareada y apenas consciente de dónde está o de qué está haciendo, inicialmente se deja seducir por él, aunque después logra escapar.

Al día siguiente, la policía la acusa de haber asesinado a su amante Courtland. Entonces, su libidinosa vida anterior sale a la luz ante los ojos de David, que la rechaza de plano. En Letty Lynton cuando Jerry conocía el pasado de Letty señalaba a los presentes que ya no vivían en la década de 1890. Casi quince años después, la regresión en materia sexual operada por la Oficina Hays es evidente.

Conforme a los preceptos de la PCA, Madeleine es procesada más por su vida inmoral que por asesinato. Al haber perdido a David, rehúsa defenderse en el juicio y los testigos se dedican a propagar su conducta licenciosa. Todos la han abandonado, excepto el Dr. Caleb. 
El largometraje tan solo esquiva a la censura en una ocasión, con la fuerte reprobación que realiza el psiquiatra de David. El fiscal lo describe como razonable e inteligente, pero Caleb matiza: "Tras conocerlo puedo comprender que la Srta. Damien se negara a sincerarse con él”. A lo que añade: “... carece de capacidad emocional e intelectual...". Y son las palabras del psiquiatra las que frenan la actitud intolerante de David. Su confesión posterior de que aún quiere a Madeleine provoca que ella decida luchar por su vida y acepte declarar, lo que conduce a la resolución del caso y al arresto del verdadero asesino.

Según AFI Catalog, el final feliz, donde David hace caso omiso a una carta de despedida de Madeleine y se reúne con ella en el aeropuerto, no figuraba en el guion y se rodó en el último momento. Es posible que Breen, tras comprobar cómo Madeleine era debidamente reprobada, desdeñada y repudiada por todos, accediera a su filmación.

\section{RESULTADOS Y CONCLUSIONES}

Tras el análisis que hemos efectuado de las dos versiones fílmicas modernizadas realizadas por Hollywood durante su periodo clásico del caso de Madeleine Smith podemos afirmar que la versión ilegítima de la obra teatral, Letty Lynton, está mucho más próxima a la historia de 1857 que la adaptación legítima, Dishonored Lady.

La película de MGM encierra la esencia del crimen de Glasgow y se erige como una adaptación fílmica actualizada bastante fiel del suceso, dado que en ella se localizan sus principales componentes: la amenaza de una joven por su anterior amante cuando ella quiere terminar la relación al comprometerse con otro; el chantaje perpetrado mediante sus apasionadas cartas; el envenenamiento; el subsiguiente asesinato; y, lo más importante, como Madeleine Smith, su protagonista es una impune asesina (Tabla 1).

Tabla 1. Elementos principales de los acontecimientos históricos y las fuentes implicadas.

\begin{tabular}{|c|c|c|c|c|c|}
\hline & $\begin{array}{c}\text { Hechos del } \\
\text { siglo XIX }\end{array}$ & Obra teatral & Novela & Film de 1932 & Film de 1947 \\
\hline Amenaza & $\mathrm{X}$ & $\mathrm{X}$ & $\mathrm{X}$ & $\mathrm{X}$ & \\
\hline $\begin{array}{c}\text { Chantaje a través } \\
\text { de las cartas }\end{array}$ & $\mathrm{X}$ & $\mathrm{X}$ & $\mathrm{X}$ & $\mathrm{X}$ & \\
\hline Envenenamiento & $\mathrm{X}$ & $\mathrm{X}$ & $\mathrm{X}$ & $\mathrm{X}$ & \\
\hline $\begin{array}{c}\text { Asesinato con- } \\
\text { sumado por la } \\
\text { heroína }\end{array}$ & $\mathrm{X}$ & $\mathrm{X}$ & $\mathrm{X}$ & $\mathrm{X}$ & \\
\hline Juicio & $\mathrm{X}$ & $\mathrm{X}$ & $\mathrm{X}$ & & $\mathrm{X}$ \\
\hline Absolución & $\mathrm{X}$ & $\mathrm{X}$ & $\mathrm{X}$ & $\mathrm{X}$ & $\mathrm{X}$ \\
\hline Final feliz & & & & $\mathrm{X}$ & $\mathrm{X}$ \\
\hline
\end{tabular}

Fuente: elaboración propia.

A la consecución de estas semejanzas contribuyeron dos factores. De un lado, su constitución efectiva a partir de tres fuentes que se combinaron para la elaboración del guion y poseían el mismo fondo argumental: los hechos del siglo XIX, la dramatización y la novela. De otro, la ausencia de una 
influencia real de la Oficina Hays sobre su contenido artístico. Es decir, tras la prohibición inicial relacionada con la no adquisición de la pieza, la producción de Letty Lynton transcurrió sin coacciones. Así se explica su tono liberal y desprovisto de prejuicios.

Sin embargo, el menoscabo de la MPPDA existió, solo que fue de otra índole. Como hemos detallado, en cierto modo la censura fue la inductora del plagio, al impedir a MGM adquirir los derechos de Dishonored Lady, y con posterioridad demostró una negligencia absoluta a la hora de proteger a la productora de una posible demanda por infracción de los derechos de autor. Las resultas de tales acciones se extienden hasta la actualidad, puesto que el acceso comercial del film continúa siendo inviable.

Por el contrario, Dishonored Lady surgió de forma única a raíz de la obra teatral, lo que implicó ya de entrada la pérdida de buena parte de los elementos del relato del siglo XIX, entre ellos el más importante las cartas (Tabla 1).

En cuanto a la acción de la censura, supuso una completa inversión de lo sucedido en Letty Lynton. Filmada en plena vigencia de la PCA y el mandato del ultracatólico y conservador Joseph I. Breen, irónicamente esta vez se permitió tanto la compra de los derechos de la obra como la utilización de su título, aunque ahí finalizaron las concesiones.

La PCA sí ejerció su potestad sobre la vertiente dramática y creativa del film. De hecho, actuó con tantas restricciones e imposiciones sobre la trama que el producto finalizado fue una versión totalmente desdibujada e irreconocible del asunto. La PCA eliminó la coacción, el chantaje y el envenenamiento, y ni siquiera existe el asesinato cometido por la heroína, que es inocente (Tabla 1). En realidad, su nombre -Madeleine Damien/Dixon- fue de lo poco que quedó. A decir verdad, la PCA terminó por configurar otra ficción, cuya premisa básica es la continua reprobación de la vida, sexual y laboral, de su protagonista. En consecuencia, aunque se rodó casi quince años después, es una película mucho más involucionada y regresiva.

A la postre, tantas alteraciones y supresiones terminaron por negarle prácticamente todo parentesco con el relato original del siglo XIX (Tabla 1). Es más, aparte del nombre de Madeleine -una cuestión superficial-, el único vestigio que podemos encontrar es un juicio, donde una mujer joven es acusada del asesinato de su ex amante y durante el cual se revela, ante la opinión pública y su prometido, su vida amorosa anterior. La absolución, presente en todos los relatos, es otro vínculo aislado.

Los nexos que alberga con Letty Lynton son igualmente tenues y escasos. Meramente podemos señalar, en primer lugar, la circunstancia única que comparten de que el ex amante es un individuo acaudalado; en segundo, el happy ending, una premisa básica del cine clásico de Hollywood, que, por ello, solo se da en los largometrajes; y, en tercero, la lascivia de las heroínas, sugerida en los dos casos como un rasgo de ascendencia genética paterna. Ahora bien ambas narraciones fílmicas toman este último motivo de la obra teatral, y en lo que atañe a Dishonored Lady no la aproxima en modo alguno a los acontecimientos de 1857. De otro lado, el juicio, que vincula a la película de 1947 con lo ocurrido en el siglo XIX, no figura en Letty Lynton, donde se sustituye por un interrogatorio policial.

Por todo lo expuesto, al ser comparadas, Dishonored Lady es inadmisible como un remake de Letty Lynton. Mientras que si la cinta de 1947 es confrontada con los hechos de Glasgow, el rastro es poco menos que remoto.

Por último, a través de este estudio de contraste se ha puesto de manifiesto el modo de proceder, harto inverso, de la Oficina Hays frente un mismo material antes y después de julio de 1934. Durante el periodo Pre-Code, cuando la censura no tenía auténtico poder ni influencia, el objetivo de la MPPDA era salvaguardar las apariencias a toda costa, sin conceder significación real al mensaje ideológico, moral o sexual de los films; de ahí que impidiera la adquisición de la pieza Dishonored Lady y la utiliza- 
ción de su título, pero permitiera que trascendiera su contenido. Justo lo opuesto sucedió en la época de la PCA, donde la censura, sabedora de su enorme autoridad, podía incluso prescindir de las cuestiones de imagen y admitir para su filmación un texto literario tachado públicamente (y por ellos mismos en el pasado) de libidinoso; poco importaba, ya que estaban seguros de que lo transformarían y llegaría a las salas de exhibición "limpio" y libre de objeciones. En esta época, lo relevante era el control sobre el fondo moral y que las cintas se presentasen ante los espectadores totalmente depuradas, aunque ostentasen designaciones escandalosas.

\section{BibLIOGRAFÍA}

\section{- Fuentes primarias:}

Armendariz Sought For Buddy Rogers Pic (30 de enero de 1946). Variety, $161(8), 9$.

Bell, T. (17 de agosto de 1944). Hollywood. Motion Picture Daily, 56(33), 10.

Coast Flashes (25 de febrero de 1944). Motion Picture Daily, 55(39), 3.

"Dishonored Lady" to be Stromberg UA Production (24 de junio de 1942). Film Daily, 81(122), 1, 6.

Hall, M. (30 de abril de 1932). Letty Lynton. New York Times, 19.

Inside Stuff-Pictures (12 de julio de 1932). Variety, 107(5), 37.

Lowndes, M. B. (1948). Letty Lynton. Barcelona, España: Luis de Caralt.

"Lynton” Starts Piracy Action Against M-G-M (28 de junio de 1932). Variety, 107(3), 10.

M-G Ducks Hays' "Dishonored” Ban By Book Title (5 de enero de 1932). Variety, 105(4), 3.

Much Litigated "Dishonored Lady" Winds Up With Original Tag at UA (17 de junio de 1942). Variety, $147(2), 22$.

Sargent, E. W. (8 de noviembre de 1932). Odd Plagiarism Angle in "Letty Lynton" Suit. Variety, $108(9), 19$.

Stromberg Back to Coast (13 de diciembre de 1944). Motion Picture Daily, 56(113), 10.

Studios Limit Takes To Two Per Scene (1 de noviembre de 1944). Motion Picture Daily, 56(85), 9.

UA Owners - Stromberg First (15 de julio de 1942). Variety, 147(6), 15.

\section{- Fuentes secundarias:}

Barton, R. (2010). Hedy Lamarr: The Most Beautiful Woman in Film. Lexington, KY: The University Press of Kentuky.

Breitenbach, E., Fleming, L., Kehoe, S. K., \& Orr, L. (Eds.) (2013). Scottish Women: A Documentary History, 1780-1914. Edimburgo, Reino Unido: Edinburgh University Press.

Brownlow, K. (1996). David Lean. A Biography. Londres, Reino Unido: Richard Cohen Books.

Decherney, P. (2012). Hollywood's Copyright Wars. Nueva York, NY: Columbia University Press.

Eyles, A. (1987). That was Hollywood: the 1930's. Londres, Reino Unido: Batsford.

González-Sampedro, I. (2014). Reivindicación de la cultura urbana en "The Role of Notable Silences in Scottish History", de A. L. Kennedy. Miscelánea: A Journal of English and American Studies, 50, $35-47$.

Guiralt Gomar, C. (2012). Fundamentos de la obra cinematográfica de Clarence Brown: Inicios y consolidación estilística en el contexto del cine clásico norteamericano entre los años 1915-1925. (Tesis doctoral). Universidad de Valencia, Valencia, España.

Gutner, H. (2001). Gowns by Adrian. Nueva York, NY: Harry N. Abrams.

Hartman, M. S. (2014). Victorian Murderesses: A True History of Thirteen Respectable French and English Women Accused of Unspeakable Crimes. Mineola, NY: Dover. 
Hischak, T. S. (2009). Broadway Plays and Musicals: Descriptions and Essential Facts of More Than 14,000 Shows through 2007. Jefferson, NC: McFarland \& Company.

Kabatchnik, A. (2010). Blood on the Stage, 1925-1950: Milestone Plays of Crime, Mystery, and Detection. Lanham, MD: Scarecrow Press.

Knox, W. W. J. (2006). Lives of Scottish Women: Women and Scottish Society, 1800-1980. Edimburgo, Reino Unido: Edinburgh University Press.

Lamarr, H. (1968). "Éxtasis” y yo. México, D.F., México: Grijalbo.

MacGowan, D. (1999). Murder in Victorian Scotland. The Trial of Madeleine Smith. Westport, CT: Praeger.

Moix, T. (1996). Mis inmortales del cine. Hollywood, años 30. Barcelona, España: Planeta.

Shearer, S. M. (2010). Beautiful: The Life of Hedy Lamarr. Nueva York, NY: St. Martin's Press.

Simkin, S. (2014). Cultural Constructions of the Femme Fatale: From Pandora's Box to Amanda Knox. Nueva York, NY: Palgrave Macmillan.

Vaidhyanathan, S. (2003). Copyrights and Copywrongs. Nueva York, NY: New York University Press.

Vieira, M. A. (1999). Sin in Soft Focus: Pre-Code Hollywood. Nueva York, NY: Harry N. Abrams.

Vieira, M. A. (2009). Irving Thalberg. Berkeley, CA: University of California Press.

Walker, A. (1983). Joan Crawford. The Ultimate Star. Londres, Reino Unido: Weidenfeld \& Nicolson.

- Bases de datos y documentos:

AFI Catalog of Feature Films (2016). The American Film Institute Catalog Database 1893-1970. Recuperado de http://www.afi.com/members/catalog/. Fecha de consulta: 1 de agosto de 2015.

Sentencias originales del proceso judicial Sheldon et al. v. Metro-Goldwyn Pictures Corporation et al., United States Federal Goverment, United States Supreme Court. Recuperadas de https://supreme.justia.com/. Fecha de consulta: 5 de agosto de 2015:

Sheldon v. Metro-Goldwyn-Pictures Corp., 7 F. Supp. 837 (S.D.N.Y. 1934).

Sheldon v. Metro-Goldwyn-Pictures Corp., 81 F.2d 49 (2d Cir. 1936). 